\title{
The Psychological Hotline Services Quality Survey during the Pandemic of COVID-19 in Mainland China
}

\author{
Xiubin Lin ${ }^{1,3}$, Joshua Swift ${ }^{2}$, Yin Cheng ${ }^{1,3}$, Qin An ${ }^{4}$, Hong Liang ${ }^{5}$, Yangsheng Wang ${ }^{3}$ and Xiaoming \\ $\mathrm{Jia}^{4, *}$ \\ ${ }^{1}$ Key Laboratory of Adolescent Cyberpsychology and Behavior (CCNU), Ministry of Education, Key Laboratory of Human \\ Development and Mental Health of Hubei Province, School of Psychology, Central China Normal University, Wuhan, 430079, \\ China \\ ${ }^{2}$ Department of Psychology, Idaho State University, Pocatello, ID 83201, USA \\ ${ }^{3}$ Hubei Oriental Insight Mental Health Institute, Wuhan, 430070, China \\ ${ }^{4}$ School of Humanities and Social Sciences, Beijing Institute of Technology, Beijing, 100081, China \\ ${ }^{5}$ Beijing Huilongguan Hospital, Beijing, 100096, China \\ *Corresponding Author: Xiaoming Jia. Email: jiaxiaoming100@126.com \\ Received: 02 April 2020; Accepted: 23 May 2020
}

\begin{abstract}
The outbreak of the COVID-19 pandemic has provoked a significant amount of panic due to dramatic changes in daily routines for residents all over China. In response, more than 600 psychological hotlines have been built or modified and have supplied mental health services for the public. Regarding the service quality of the hotlines, a survey has been conducted to investigate the running of hotline services during the COVID-19 pandemic. The results reveal that the more successful hotlines all had better trained hotline counselors, and in the meanwhile, the key features of providing supervision arrangements and training resources. Moreover, the referral list should be adjusted according to the accessibility of the recourses during the pandemic.
\end{abstract}

Keywords: Psychological hotlines; service quality; COVID-19; China

The outbreak of the COVID-19 pandemic not only triggered a historic decline of social and economic activity in China, it also provoked a significant amount of panic due to dramatic changes in daily routines for residents all over the country. In the past, when faced with disasters like earthquake or flood, several psychological resources were available to help alleviate the distress and pain experienced by the general population. However, during this pandemic, many of those resources were unavailable given that most of the psychological professionals were required to isolate from others in order to help slow the transmission of the disease. In response, more than 600 psychological hotlines have been built or modified in a short period of time, not to mention almost all universities opened up their own hotline for their own students which are not included in the number of 600 , with the encouragement of the Chinese government [1,2] and with support from several professional associations in China. The very first series of during-pandemichotline might be built around January $23^{\text {th }}$ to $27^{\text {th }}[3,4]$, the very same period of the Wuhan lockdown, and they have immediately begin to supply service to the entire public who were impacted by the pandemic. Later, as additional hotlines were developed, several began targeting specific groups of the populationsuch as patients of COVID-19, children and teenagers, doctors and nurses who worked on the front lines, police, etc.

Building a high-quality psychological hotline is not an easy task, especially within such a short period of time and given that all of the set-up, management, and training needed to be completed remotely due to isolation requirements. In an effort to better understand the development and utility of these hotlines, two highly valued national professional organizations (the Clinical and Counseling Psychology Committee of 
the Chinese Psychological Society and the Clinical Psychology Registration Work Committee of the Chinese Psychological Society) recently launched a survey investigating the running of hotline services during the COVID-19 pandemic. In conducting this survey, administrators of the hotlines were invented to complete a questionnaire regarding the origin, affiliation, management, resources, and services offered of their respective hotlines. From February $15^{\text {th }}$ to April $16^{\text {th }}$, there are 414 psychological hotline administrators have responded to the survey. The results have revealed some crucial messages that could help facilitate the future development of psychological hotline services when there is an immediate need.

First, results from the survey indicate that hotline and online mental health services in this period of time are most frequently coming from five different sectors, including the medical system ${ }^{1}$, educational system $^{2}$, private practice, professional associations, and local governmental departments. At the very beginning of the outbreak, the Chinese Ministry of Education and the Chinese National Health Commission both published documents which encouraged medical institutes and universities which had enough recourses to open up services to help to maintain the mental health of the public. These services were especially meant to help those who worked on the frontline during the lock down, including doctors, nurses, police, community workers, etc. [1,2]. Even before that though, several psychological crisis hotlines had been built within the medical system long before this outbreak [5]. The existing hotlines were instrumental in providing services while new ones were developed. One of the most well-known and respected of the existing hotlines is the Beijing Huilongguan hospital crisis hotline, which has been running for more than a decade. In contrast to the existing hotlines within the medical system, several hotlines were able to quickly develop within the educational system. The ease of development for these hotlines was likely due to having a large number of knowledgeable and trained psychology students and faculty, who could quickly volunteer as service suppliers. Examples of this are three during-epidemic-hotlines which were developed by Tsinghua University, Beijing Normal University, and Central China Normal University, respectively. These universities all have high quality counseling or clinical psychology graduate programs and/or wellfunctioning counseling centers. Since their development, these hotlines have been able to provide care to a large number of individuals and have received praise from psychological professionals throughout the country. With the development of mental health care in China over the years, more and more private practice institutes have been built, and they now serve as an important force at this time. Several hotlines had already been developed within the private practice system, but the number nearly doubled after the COVID-19 outbreak. Last, professional organizations and local governmental departments, such as the Civil Administration and the Women's Federation of local government, have also devoted resources to building additional psychological hotlines in response to the pandemic. The details of the source of the hotlines can been seen in Tab. 1.

Table 1: The source of the hotlines

\begin{tabular}{llllllll}
\hline & Medical & Educational & $\begin{array}{l}\text { Private } \\
\text { Practice }\end{array}$ & $\begin{array}{l}\text { Professional } \\
\text { Associations }\end{array}$ & $\begin{array}{l}\text { Government } \\
\text { Department }\end{array}$ & Unknown & Total \\
\hline $\begin{array}{l}\text { Long-term } \\
\text { Hotlines }\end{array}$ & 122 & 21 & 43 & 21 & 21 & 1 & 229 \\
$\begin{array}{l}\text { Pandemic } \\
\text { Only }\end{array}$ & 43 & 66 & 31 & 17 & 13 & 3 & 173 \\
Unknown & 9 & 0 & 1 & 1 & 1 & 1 & 12 \\
Total & 174 & 87 & 75 & 38 & 35 & 5 & 414 \\
\hline
\end{tabular}

${ }^{1}$ Which indicated that the hotlines are managed by doctors or departments of mental health or psychiatry.

${ }^{2}$ Which indicated that the hotlines are managed by university counseling centers or departments of psychology. 
In the current survey, we also attempted to evaluate the quality of the psychological hotline services from each of five dimensions. These five dimensions were identified by the researchers based on a separate set of interviews that were conducted with four experts who each had more than ten years of experience in running hotlines. Interestingly, the experts were in high agreement about what makes a hotline successful. As such, questions were asked about the type of facilities (e.g., location, resources), qualification of counselors, norms of service (e.g., referral list, crisis management plan, service process), management efforts (e.g., staff, management regulation and the implement of ethical code), and training and supervision.

In terms of facilities and resources, the survey results suggested that the newer hotlines had a harder time getting facilities, such as local phone numbers with multiple lines. For example, at the time of the survey, 108 of the hotlines $(26.09 \%)$ did not have a local phone number. Of the hotlines that did have a local phone number $(n=306)$, only 41 of them $(9.9 \%)$ had a toll-free phone number. Thus, it appears that facility issues may be a limitation that prevents the hotlines from reaching more people. To deal with these types of issues though, some of the hotlines have employed instant messaging apps, such as QQ. This particular app is popular in China, and it allows two-way communication through audio, video, or text.

Historically, hotline services have served as a supplement to traditional psychological services. The hotlines were typically staffed by para-professional volunteers, and the major function was limited to providing support and referral information to those who were in a temporary crisis situation [6,7]. This picture has changed in the midst of the current pandemic. The results of the survey indicate that $90.34 \%$ (n $=387$ ) of the hotlines require their service providers to either possess an academic diploma in psychiatry, social work, or psychology, or have a recognized certification as a counselor or psychotherapist. In fact, some of the top hotlines have hundreds of certificated counselors who are well-trained and have full-time job in universities, hospitals, or practice settings and worked as a mental health practitioner currently, but have voluntarily joined the hotlines during the pandemic. The way most new hotlines connected with the supplier, especially those built for the COVID-19 pandemic, was to post their recruiting information online, such as through social media outlets. This online format led to recruiting information spreading relatively fast within the mental health service community. Take the joint hotline built by Ministry of Education and Central China Normal University as an example. Through recruiting on the WeChat Platform, more than 4,000 individuals filled out an application to voluntarily join to be a hotline counselor within three days. And more than 3000 were admitted, while most of whom were professionals in the field of psychological or mental health, including some professionals overseas. This exact hotline holds more than 30 lines work all together, and works 24 hours a day, seven days a week. It could be the biggest during-pandemic hotline in Mainland China.

The survey results also indicated that almost all the psychological hotlines had set standards or norms of service in place. This was even common in the newly developed hotlines. Seventy-eight percent $(\mathrm{n}=$ $323)$ of the hotlines had written regulatory procedure documents and $92 \%(\mathrm{n}=381)$ had full time administrators managing the regulations during the pandemic, with just over $75 \%(n=311)$ having both. Although referral lists were commonly available, most of the pre-existing hotlines had referral resources that typically did not fit the current state of the pandemic (i.e., many of the resources were not available given isolation requirements). Thus, there was a high need for pandemic-specific referral resources. In fact, high and low-performance hotlines often differed in whether they had a tailored resource list-almost all high-performance hotlines had a pandemic-specific referral list while less than half $(46 \%)$ of the lowscoring hotlines did.

The results of the survey suggested that the main difference between the best psychological hotlines and those in need of improvement was whether good supervision and training resources were made available to the service providers. Within China, prior to the pandemic, the supply of competent mental health providers already fell short of the mental health demands in the population [8-10]. As such, educational and practice standards of competence were being developed. In the midst of the COVID-19 pandemic, the shortfall of competence became more severe given that even professionals with many years of experience had typically not developed sufficient knowledge and skills in providing psychological hotline interventions under the circumstance of a global contagion. Fortunately, $89.86 \%$ of the investigated 
hotlines had arranged for crisis intervention training for their service providers, and $69.81 \%$ of the hotlines had arranged regular supervision on a weekly or monthly basis (peer supervision was not included in calculating this percentage). Interestingly, almost all the top performing hotlines provided even more frequent supervision on a daily basis or twice or three times a week, while only half to two-thirds of the low performing hotlines were struggling have a monthly basis supervision. Supervisory resources are limited in China typically; however, several professional organizations have made declarations about the importance of providing voluntary support and supervision for service providers during the current pandemic (e.g., the declaration of Clinical Psychology Registration Work Committee of the Chinese Psychological Society [11]).

At the very beginning, the purpose of the survey was to help the help seekers to find high-quality hotlines that could fulfill their needs among more than 600 hotlines. However, with the progressing of this survey, a better understanding of psychological hotlines in the midst of the COVID-19 pandemic and to further consider factors or necessities that might lead to a hotline's success was gained. The more successful hotlines all had the key feature of providing supervision arrangements and training resources. Interestingly, this also meets a broader need in China based on the current development stage of Chinese mental health service professionals. High performing hotlines also had tailored referral lists for the pandemic. We strongly recommend that all hotlines develop or revise their referral lists so that they fit the current COVID-19 situation. These referral lists should also regularly be updated to reflect available resources as this, or future, crisis situations evolve. In conclusion, it is clear that the effort to build and run a hotline during this period of time should be applauded, as it represents a Herculean task that requires the overcoming of several difficulties (e.g., recruiting and training professionals, facility development, developing standards of care). However, with significant efforts in place, such as those demonstrated by the high performing hotlines, hotlines may be well-equipped to provide high quality mental health services to those in need when other traditional psychological services may be unavailable. These results present preliminary findings on Chinese hotline service quality. More detailed research is needed to further explore ways to enhance hotline service ability and quality. In future research, it will be necessary to focus not only on the arrangement and basic information of the hotlines, but also to learn about the real performance of the hotline counselors and the efficacy of their interventions, which is the heart and soul of mental health services.

Acknowledgement: This research has been greatly supported by the Clinical and Counseling Psychology Committee of the Chinese Psychological Society and the Clinical Psychology Registration Work Committee of the Chinese Psychological Society.

Funding Statement: This research has funded by Chenzhonggeng Clinical and Counseling Psychology Development Fund, No. 2020SJ001(JD) (URL: http://www.psy.pku.edu.cn/). Oriental Insight Mental Health Research Fund (URL: http://www.dfmjxl.cn/).

Conflicts of Interest: The authors declare that they have no conflicts of interest to report regarding the present study.

\section{References}

1. Ministry of Education of the People's Republic of China. (2020). The arrangement of opening hotline and online mental health service (in Chinese). Retrieved from:

http://www.moe.gov.cn/jyb_xwfb/gzdt_gzdt/s5987/202001/t20200128_416721.html.

2. National Health Commission of the People's Republic of China. (2020). Guidelines for psychological assistance hotlines during 2019-nCoV pneumonia epidemic (in Chinese). Retrieved from: http://www.nhc.gov.cn/jkj/s3577/202002/f389f20cc1174b21b981ea2919beb8b0.shtml.

3. Beijing Youth Daily. (2020). Psychological counseling growing during pandemic (in Chinese). Retrieved from: http://epaper.ynet.com/html/2020-01/30/content_347986.htm?div=-1.

4. Beijing Normal University. (2020). 4001888976, Beijing Normal University have opened up counseling hotline service (in Chinese). Retrieved from: https://www.thepaper.cn/newsDetail_forward_5651309. 
5. National Health Commission of the People's Republic of China. (2010). The office of Ministry of Health's notice on further standardizing the management of psychological aid hotline (in Chinese).

6. Rosenbaum, A., Calhoun, J. F. (1977). The use of the telephone hotline in crisis intervention: a review. Journal of Community Psychology, 5(4), 325-339.

7. Kalafat, J., Gould, M. S., Munfakh, J. L. H., Kleinman, M. (2011). An evaluation of crisis hotline outcomes. Part 1: nonsuicidal crisis callers. Suicide \& Life-Threatening Behavior, 37(3), 322-337.

8. Lin, X., Jiang, G., Duan, C. (2016). Necessity and urgency of increasing graduate training in Chinese clinical and counseling psychology: Wuhan declaration. Psychotherapy Bulletin, 51(4), 26-29.

9. Qin, M., Qian, M., Chen, H., Zhong, J., Yao, P. et al. (2008). An investigation of professional personnel and practice in psychotherapy and counseling in six major areas of China. Psychological Science, 31(5), 1233-1237.

10. Ng, R. M. K., Lee, C. K., Liu, J., Luo, J., Zu, S. et al. (2017). Psychotherapy services in China: current provisions and future development. Journal of Contemporary Psychotherapy, 47(2), 87-94.

11. Clinical Psychology Registration Work Committee of the Chinese Psychological Society (2020). The list of registration supervisor who offers voluntary supervision during the epidemic of COVID-19. Retrieved from: https://mp.weixin.qq.com/s/fo2uCCXkMt JQ0N7AOgg6w. 